\title{
Die bisherigen sero-therapeutischen Bestrebungen bei Tuberkulose.
}

\author{
Von
}

Paul Piel, Düsseldorf, Medizinalpraktikant.

Nachdem die erste Ära der Behandlung der Tuberkulose mit dem Koch'schen Tuberkulin wenig ermutigende Erfahrungen gezeitigt hatte, ist nur an wenigen Stellen in vorsichtiger Weise die spezifische Behandlung der Tuberkulose weiter geführt worden

Seit 8--10 Jahren ungefähr gewinnt die Behandlung der verschiedenen Formen der Tuberkulose mit verschiedenen TuberkulinPräparaten wieder immer mehr an Boden.

Es ist heute aber noch nicht möglich, ein abschliessendes Urteil über die Erfolge dieses Vorgehens zu fällen zu einer Zeit, wo wir uns noch nicht einmal darüber klar sind, ob wir mit Sahli die minimalsten Mengen von Tuberkulin wählen sollen, bei peinlichster Ver: meidung jeglicher Reaktion, oder ob wir trotz Reaktion mit der Dosis steigen sollen, wie es z. B. die Schlossmann'sche Klinik bei Säuglingen seinerzeit getan hat.

Es ist ganz klar, dass ein tuberkulöser Säuglingsorganismus ganz anders reagiert wie tuberkulöse Erwachsene. Und ist es ganz sicher, dass die verschiedenen Formen der Tuberkulose (die mehr lokalisierten chirurgischen und die Drüsentuberkulosen, wie sie besonders bei Kindern vorliegen, andererseits die mehr destruierenden Lungentuberkulosen bei Erwachsenen) auf Tuberkulin in ganz verschiedener Weise reagieren müssen.

Hierin können nur ausgedehnte Untersuchungen Klarheit bringen, die serologisch, wie klinisch and anatomisch mit den modernsten 
Hilfsmitteln der Untersuchung den Verlauf unter den verschiedensten Verhältnissen genau verfolgen.

Während wir uns hier noch an der detaillierten Bearbeitung dieser spezifischen Therapie der Tuberkulose befinden, ist von anderer Seite bereits ein von diesem Vorgehen divergierender Weg vorgeschlagen worden, dessen Prinzip darin besteht, die im Tierexperiment gegen den menschlichen Tuberkelbazillus gewonnenen Immunstoffe den tuberkulosenkranken Menschen einzuverleiben.

Über die bisherigen Bestrebungen und Resultate dieser serotherapeutischen Untersuchungen soll im folgenden berichtet werden.

Nach einer kurzen historischen Entwicklung werden wir uns nur mit denjenigen Autoren ausführlich befässen, deren Untersuchungen und Beobachtungen sich auf ein grosses Material stützen.

Die ersten Versuche einer passiven Immunisierung wurden im Jahre 1890 von Bertin und Picq (4) angestellt. Sie beruhen auf der Anwendung des Blutes von Tieren, von denen angenommen wurde, dass sie gegen Tuberkulose von $\mathrm{Natur}$ aus immun wären.

Die beiden erwähnten Autoren konnten durch Transfusion von Ziegenblut bei Kaninchen einen ,bakteriziden Zustand" erzeugen, wodurch die Tiere der Infektion widerstanden haben sollen. Diese Immunisierung gelang jedoch nur, wenn die Transfusion zur selben Zeit wie die Infektion stattfand. Auf Grund dieser Experimente wurde eine Ziegenbluttransfusion $(12-15 \mathrm{~g})$ bei einem Schwindsüchtigen ins subkutane Gewebe gemacht. Das Allgemeinbefinden soll sich danach gebessert haben, der Lungenbefund blieb der gleiche.

Richet und Héricourt (34) wollten Kaninchen durch Injektion von Hundeblut gegen Tuberkulose immunisieren. Die Versuche misslangen, die Tiere starben. Sie kamen später auf den Gedanken, die antituberkulösen Eigenschaften des Hundeblutes dadurch zu verstärken, dass sie Hunde mit den Bazillen der Geflügel-Tuberkulose impften, in der Vermutung, dass dieses Serum dann Antitoxine nach dem Vorbild des antidiphtherischen und antitetanischen Serums enthalte. Das Blut dieser ,tuberkulisierten" Hunde diente nun als Transfusionsmittel.

Die Versuchstiere lebten noch nach 3 Monaten, während die Kontrolltiere bereits innerhalb 4 Wochen an Tuberkulose starben. Versuche beim Menschen wurden keine angestellt,

Die Wirkung des Blutes schlossen die Autoren lediglich aus dem Lebenbleiben der Versuchstiere; Sektionen wurden nicht vorgenommen. Dies waren Versuche mit Transfusion des gesamten Blutgewebes. 
Die erste ,S e r o therapie“ wurde von Bra ncac ci o und S ol a ro o(5) vorgenommen. Sie injizierten Lungenkranken das Serum von nicht vorbehandelten Hunden. Sie stiegen dabei in ihren Dosen bis zu $92 \mathrm{~g}$ bei 54 -Injektionen. Sie beobachteten bei den so behandelten Kranken folgende Veränderungen: Das Gewicht nahm in 2 Fällen $a b$ und in 2 Fällen etwas zu; die Temperatur blieb unbeeinflusst; Bazillen waren nach wie vor im Sputum vorhanden; in 2 Fällen soll sich der Lungenbefund gebessert haben. Lokale oder allgemeine Reaktionen traten infolge der Injektionen nicht auf.

Bernheim (3) (1894) ging schon einen Schritt weiter, er behandelte die menschliche Tuberkulose mit "Immun-Serum". Das Serum gewann er von Tieren, die er mit grossen Mengen von auf $80^{\circ}$ erhitzten und dann filtrierten Tuberkelbazillenkulturen injiziert hatte.

Zeigte sich bei den Tieren keine schädigende Wirkung infolge dieser Einspritzungen, so kamen sie zur Sektion. Mit dem ron diesen Tieren erhaltenen Serum wurden Schwindsüchtige in Dosen von $2-5 \mathrm{ccm} 5-7$ Monate lang behandelt.

Bernheim will auf diese Weise die beginnende Tuberkulose mit' Erfolg bekämpft haben. Nach seiner Ansicht würden durch sein Serum die ,zahlreichen Gifte, welche den Organismus des Tuberkulösen vergiften, zerstört; die Kraft der Leukozyten würde zunehmen und schliesslich das Übergewicht über die Bakterien erhalten".

Ein ähnliches Verfahren schlug Babes (1) ein; auch ihm will es gelungen sein, bei Hunden durch intravenöse Injektion von Tuberkelbazillen und Tuberkulin die Immunität der Hunde gegen Tuberkulose zu erhöhen.

Mit dem Serum dieser immunisierten Hunde machte er Versuche an Hunden, Kaninchen und Meerschweinchen, um dieselben hierdurch gegen Tuberkulose passiv zu immunisieren oder von Tuberkulose zu heilen. Der Einfluss des Serums solcher Tiere auf die Tuberkulose der Kaninchen war günstig. Doch da es nicht bekannt ist, mit welcher Art von Tuberkelbazillen - dem humanen oder bovinen Typus - die Kaninchen infiziert wurden, so können die Resultate dieser Versuche nicht als beweiskräftig gelten.

Dieselben Einwände beziehen sich auch auf das Serum Patersons (32), der mit Erfolg die Tuberkulose der Kaninchen und Meerschweinchen mit Serum von Hühnern behandelte, die mit Kulturen der Vogeltuberkulose immunisiert worden waren.

Das erste antitoxische und "antibazilläre" Serum stammt von Niem ann (31).

Zur: Darstellung seines Tuberkuloseantitoxins behandelte Niemann junge Ziegen mit einem Tuberkulin, das er aus einer hoch- 
virulenten Tuberkelbazillenkultur (gezüchtet aus einer Lungenkaverne) dargestellt hatte. Später injizierte er diesen Ziegen einen alkoholischen Niederschlag des Tuberkulins, von dem $\mathrm{Niemann}$ annahm, dass er eine „ungemein toxische" Eigenschaft besässe. Durch allmähliche Steigerung der täglichen Dosen glaubte er den Tieren grosse Mengen des wirksamen Prinzips des Tuberkulins einzuverleiben. Injizierte er das Serum der so vorbehandelten Tiere tuberkulösen Meerschweinchen, so starben diese bereits nach einigen Stunden. Von den vorbehandelten Ziegen jedoch sollen diese, ,schädlichen Tuberkulingifte" in kürzester Zeit ausgeschieden werden und an ihre Stelle - durch die Gegenwart der Tuberkuline angeregt - spezifische Antikörper treten. Nun injizierte er denselben Ziegen Tuberkelbazillen in ansteigenden Dosen, wodurch dasselbe Serum therapeutische Eigenschaften in bezug auf frische Tuberkulose der Meerschweinchen annehmen sollte. Denn 1,5 ccm dieses Serums genügten, um 30 Tage lang tuberkulöse Meerschweinchen selbst vor der doppelten tödlichen Dosis Tuberkulin zu schützen.

Niemann nahm bei leichteren Graden der menschlichen Tuberkulose Versuche vor. Die Resultate sollen günstig gewesen sein: Besserung des Allgemeinbefindens, Verschwinden der Tuberkelbazillen im Sputum, Verminderung von Husten und Auswurf. Über tatsächliche Heilung konnte er nicht berichten.

Ein antitoxisches antituberkulöses Serum, das zum ersten Mal in grossem Massstabe beim Menschen angewendet wurde, ist von M a ragliano (25) dargestellt worden. Auf Grund seiner Versuche bei Tieren kam Maragliano (1895) zur Ansicht, dass der tierische Organismus zweierlei Verteidigungsmittel gegen die Tuberkulose zur Verfügung hat. Das eine besteht in „Energie" resp. Antitoxinen, mit. denen der gesunde Organismus gewöhnlich ausgerüstet ist und welche ihn an und für sich vor der Wirkung der Tuberkelbazillen und ihrer Gifte schützen können; das andere aus solchen „Energien", die sich erst bei dem Vorhandensein der Bazillen und ihrer Gifte entwickeln. Des weiteren konstatierte er, dass das normale Blutserum von Tieren bakterizide, antitoxische und agglutinierende Eigenschaften besitzt, die sich in merklicher Weise vermehren, wenn man einem gesunden Tiere Körper abgetöteter Tuberkelbazillen oder lebende Tuberkelbazillen einspritzt. In den Geweben der Tiere vermehrt sich dann die die Tuberkelbazillen zerstörende Kraft. Angesichts dieser Tatsache legte er sich die Frage vor, ob es möglich sei, den im Kampfe gegen die Tuberkelbazillen sich befindenden Organismus diejenigen spezifischen Mittel, die er selbst nicht in genügender Quantität erzeugte, oder welche er zu bilden überhaupt nicht imstande ist, zu- 
zuführen. Er war der Ansicht, die Wirkung der Tuberkelbazillen beruhe während ihres Lebens auf Ausscheidung von Toxinen und nach ihrem Tode von giftigen Proteinen, als Produkten der Bakteriolyse. Maragliano bereitete, von dieser Annahme ausgehend, einen zusammengesetzten Impfstoff, aus dem Toxalbumin von lebenden Bazillen in flüssigen Nährböden ausgeschieden wird und aus dem Protein der abgestorbenen, Bazillenkörper.

Um dàs Toxalbumin zu erhalten, lässt Ma ragliano 4-6wöchentliche Bouillonkulturen mit einem Glyzerinzusatz durch ein Char d in'sches Filter fliessen; das so erhaltene Filtrat filtriert er nochmals durch eine Chamberlandsche Kerze. Das Protein wird aus den auf dem Filter zurückgebliebenen Bazillenkörpern ausgelaugt. $\mathrm{Zu}$ diesem Zweck wird der Filterrückstand getrocknet und in einem Mörser pulverisiert, dann Wasser in der doppelten Menge der Kulturflüssigkeit zugesetzt und das ganze im Wasserbade bei $90-9 \tilde{0}^{\circ} \mathrm{im}$ Laufe von 3 Tagen bị 10 Stunden täglich belassen. Nach Abdampfung der Flüssigkeit bis zu $1 / 10$ des ursprünglichen Volumens und Durchlassung durch ein Porzellanfilter wird das sogenannte wässerige Tuberkulin erhalten, welches alle Tuberkelproteine enthalten soll.

Der Impfstoff besteht aus Toxalbumin mit Protein im Verhältnis 1:3 vermischt. Dieser Impfstoff wird Pferden subkutan in ansteigender Dosis von 5-50 ccm eingespritzt. Nach Ablauf von 4 bis 6 Monaten werden den Pferden gegen 3 Liter Blut abgelassen, und man erhält daraus ein Serum, welches sowohl antitoxische wie antibakterielle Eigenschaften besitzen soll.

Was die Behandlung tuberkulöser Kranker mit seinem Serum anbetrifft, so applizierte es Maragliano im Laufe von 6 Wochen, indem er jeden zweiten Tag $1 \mathrm{ccm}$ injizierte und dann die Dosis bis auf $100 \mathrm{ccm}$ steigerte. Nach diesen Injektionen glaubte Maragliano eine bedeutende Zunahme an spezifischen Schutzstoffen im Serum der behändelten Kranken (allerdings nur aus der klinischen Beobachtung) konstatieren zu können. Der klinische Heilwert sollte darin bestehen, dass im allgemeinen das Fieber sank, und die Schweissabsonderung geringer, oft gar zum Verschwinden gebracht wurde, das Körpergewicht zunahm, Husten und Auswurf geringer wurden, und die Bazillen im Sputum nicht mehr nachzuweisen waren; kurzum das klinische Bild war das der vollständigen Heilung. Allerdings zeigte sich dieser günstige Erfolg nur dann, wenn es sich um eine beginnende Tuberkulose ohne jede Mischinfektion handelte.

Nach den Untersuchungen von Karwacki (19) zeigte es sich nun, dass die mit Serum Maraglianos behandelten tuberkulösen Meerschweinchen und Kaninchen viel rascher starben als die Un- 
behandelten. Nach K a r wacki lässt sich diese Serumwirkung auf die Auflösung des Bazillus im Organismus und demnach auf Vergiftung mit Tuberkelproteinen zurückführen.

Das Antituberkulose-Serum Maraglianos wurde in Italien vielfach angewandt, recht wenig in anderen Ländern. Maragliano glaubt aus der Menge des von ihm geforderten Serums schliessen zu können, dass bis zum Jahre 1905 etwa 20000 Tuberkulöse nach seiner Methode behandelt wurden.

Die Art der Applikation seines Serums erfuhr im Laufe der klinischen Erfahrung verschiedene Änderungen. Als die beste Methode stellte sich die der gemischten Immunisierung heraus, zuerst passiv, daraufaktiv. Maraglian o bezeichnete dieses Verfahren als ,p pro gressive Immunisierung". Er verfuhr dabei folgendermassen: Nach einer Periode der Injektion mit einem an Antikörpern speziell aus Antitoxinen reichen Serum - und zwar jeden zweiten Tag $1 \mathrm{ccm} 20$ Tage. lang - wird in einer zweiten Periode -das gleiche Serum mit mazerieritem Bazillenextrakt in progressiv wachsender Quantität injiziert. Dann folgte eine dritte Periode, in welcher er das Bazillenextrakt. in wässeriger Lösung rein und in ansteigender Dosis von $1 \mathrm{mg}$ bis. $5 \mathrm{mg}$ injizierte. Durch dieses Verfahren soll es. ihm gelungen sein, bereits innerhalb 3-4 Monaten ein ursprüngliches Agglutinationsvermögen im Verhältnis 1:5 auf.1:100 zu steigern.

Günstige Resultate wurden eigentlich nur in Italien erzielt, während in anderen Ländern - Frankreich, Deutschland und Russland dem Serum Maraglianos jede spezifische Heilkraft abgesprochen wurde. Ein Mitarbeiter Maragli a nos, Mir coli (28) veröffentlichte auf dem Tuberkulose-Kongress in Neapel (1905) eine Statistik, diesich auf 2890 mit Serum "Maragliano" behandelte Tuberkulösebezog. Aus derselben ging hervor, dass von 250 Fällen von umschriebener fieberloser Tuberkulose $38 \%$ geheilt, $49 \%$ auf dem Wege der Besserung waren, dass ferner von 938 Fällen mit umschriebener fieberhafter Tuberkulose $18 \%$ geheilt und $54 \%$ gebessert wurden. Unter 665 Fällen mit tuberkulöser diffuser Bronchopneumonie o hn e Mischinfektion heilten $14 \%$; gebessert wurden $43 \%$; von 332 Fällen mit diffuser Bronchopneumonie mit Mischinfektion genasen noch $9 \%$ und $36 \%$ wurden gebessert. Von 712 Fällen mit. Kavernenerscheinungen wurden noch $6 \%$ geheilt und $40 \%$ zeigten sich gebessert. Bei $46 \%$ von fieberhaften Kranken verschwand das. Fieber.

Maraglia n o selbst erzielte „Dauerheilung“ insofern, als in einem Zeitraum von 7-9. Jabren keine Rezidive aufgetreten sein sollen (in diesem Falle darf man wohl einige Zweifel an der strengen Objek- 
tivität des Autors hegen). Die besten Resultate sah er bei ambulatorisch behandelten Kranken aus dem einfachen Grunde, weil die in die Klinik Eingelieferten zumeist im Zustande vorgeschrittener Tuberkulose waren, d. h., wenn aus der lokalisierten, inzipienten Tuberkulose eine progressive, chronische tuberkulöse Phthise entstanden war. Denn ohne Mithilfe des kranken Organismus, das gibt Ma ragliano selbst zu, kann auch sein Serum keine Heilung verschaffen. Da uns nicht alle einschlägigen Arbeiten über das Serum-Maragliano zugänglich waren, lassen. wir nun einige Veröffentlichungen folgen, die aus Referaten der Zeitschrift für Tuberkulose, dem Zentralblatt für Bakteriologie und der Münchener medizinischen Wochenschrift entnommen sind.

Marzagalli (27) konnte die Wirkung des Maraglianoschen Serums beim Tierexperiment bestätigen. Bei endoperitonealen Injektionen von antituberkulösem Serum zugleich mit lebenden Bazillen injiziert, hält es die ,Toxämie" hintan und bewirkt eine langsame Infektion. Auch in Fällen von Infektionen, welche durch grosse Mengen von Bazillen hervorgerufen sind, gelang es ihm, durch das Serum längere Zeit tuberkulöse Zerstörungen zurück zu halten.

Ferrer Piera (9), Primärarzt am grossen Krankenhaus zu Barcelona, hatte desgleichen günstige Resultate mit dem Maraglianoschen Serum; es sei ihm ohne Frage die Wirkung zuzusprechen, dass es die Tuberkulose-Toxine neutralisiere. Er streift die Frage, wesbalb diese günstige Wirkung nicht in allen Fällen auftritt. Der Grund liegt seiner Ansicht nach in verschiedenen Eigentümlichkeiten der Tuberkulosebazillen-Varietäten. Nicht alle Toxine des Kochschen Bazillus wären imstande, Antitoxine zu erzeugen. Nach Ansicht dieses Autors : würden nur die Toxine derjenigen Bazillen neutralisiert, die ,eine spärliche Quantität nekrotisierenden Toxins erzeugen, und welche die nicht destruktiven Formen der Tuberkulose schaffen". Diese Toxine würden auf dem Wege der Phagozytose (vgl. u. Neporoschny) zerstört und ergäben die günstigen Resultate.

Viccolini (40) konnte von 7 Fällen, die mit Serum-Maragliano behandelt wurden, in 4 Fällen klinische Heilung der tuberkulösen Prozesse und in 2 Fällen Besserung im Allgemeinbefinden konstatieren.

Figari (10) versuchte an 2 tuberkulös gemachten Affen die Wirkung des Maraglianoschen Serums; die Tiere besserten sich nicht nur, sondern sie genasen. Er konstatierte, dass das Serum die Entwickelung der Tuberkelbazillen in vivo wie in vitro verhindere.

Soriani (37) spritzte z. T. schweren Fällen von Tuberkulose 
das Serum ohne Anwendung sonstiger therapeutischer Mittel ein; er war mit seinen Erfolgen durchaus zufrieden.

$\mathrm{Ca} \mathrm{mbias}$ o (8) berichtet über 100 Fälle von Lungentuberkulose, die er mit Serum Maragliano behandelte; nach 2-7 Jahren erwiesen Sie sich noch als gesund.

Das Antituberkulose-Serum M a raglianos fand scheinbar über die Grenzen Italiens wenig Anwendung, da in Referaten wie in den bekanntesten medizinischen Zeitschriften über Resultate mit dem Serum in anderen Ländern nichts veröffentlicht wurde.

F. Kraus, Berlin (22) sagt in seinem Artikel ,Immunität bei Tuberkulose" über das Serum von Maragliano: „Meines Wissens ist aber seine therapeutische Verwendung (gemeint ist das Serum Maraglianos) in Deutschland und in Osterreich keine sehr erhebliche: Ich selbst möchte mich nach dem, allerdings an kleinem Material selbst gemachten Erfahrungen, kaum zustimmend verhalten."

Pawlowsky, Kiew (33) urteilt zusammenfassend über das Serum Maraglianos, dass die beim Menschen erzielten Resultate in Italien recht widerspruchsvoll seien, in Frankreich, Deutschland und Russland wären die Resultate negative gewesen.

Aufähnlichen theoretischen Wegen bewegtsich Nepor o s ch n y (30) der seine Hypothesen durch verschiedene experimentelle Untersuchungen zu stïtzen sucht.

Neporoschny (30) veröffentlichte 1908, dass es ihm gelungen sei, mit einem von ihm dargestellten und ausgearbeiteten Antituberkulose-Serum künstlich hervorgerufene Tuberkulose bei Meerschweinchen zu heilen. Er behandelte mit seinem Serum 417 Meerschweinchen und erzielte angeblich bei $57 \%$ Genesung von der Tuberkulose. Die Resultate wurden durch mikroskopische Untersuchungen der Organe der mit dem Serum behandelten Tiere und Kontrolltiere geprüft. Bei den Versuchstieren, bei denen die Behandlung unmittelbar nach der Infektion einsetzte, konnte man ausser Spuren tuberkulôser Erkrankung in den Leistendrüsen und in den inneren Organen keine pathologischen Prozesse nachweissn. Interessant wären nun die morphologischen Veränderungen, die Neporoschny makkroskopisch wie mikroskopisch bei den Tieren nachweisen konnte, die erst nach verschiedenen Zeiten mit seinem Serum behandelt wurden. Z. B. bei einem Tiere, bei welchem die Behandlung erst 18 Tage nach der Infektion einsetzte, wo also die Tuberkulose die Mehrzahl der inneren Organe ergreifen und in ihnen bedeutende Verheerungen anrichten konnte, wurde der pathologische Prozess im Vordringen aufgehalten. Bei diesen und anderen Versuchstieren schrumpften die tuberkulösen Herde narbig ein und ver- 
heilten dadurch. Mikroskopisch konnte man in dem angegriffenen Lungengewebe Riesenzellen sehen, in deren Innerem sich allerkleinste Körner befanden; Tuberkelbazillen konnten in ihnen nicht nachgewiesen werden. Im Gegensatz zum gewöhnlichen pathologischen Prozess waren die Riesenzellen nicht von epitheloiden Zellen und starken kleinzelligen Infiltraten umgeben, sondern von einem äusserst feinen, grossmaschigen Netz von Bindegewebsfasern, die sich später zu derbem Bindegewebe vérdickten, die Riesenzelle allmählich von der Umgebung isolierten, um schliesslich ganz von den eindringenden Leukozyten verschlungen zu werden.

Im mikroskopischen Bild sah er weiter, dass sowohl die Tuberkelbazillen wie die Detritusmassen von Leukozyten direkt vernichtet und aufgebraucht wurden. Nach Neporoschnys Ansicht fällt diese Aufgabe den einkernigen Phagozyten zu, in ihrem Inneren konnte er mehr oder weniger destruierte. Tuberkelbazillen bemerken.

Bei der Herstellung seines antituberkulösen Serums liess sich Neporoschny von dem Grundgedanken leiten, Tuberkelbazillen mittels einkerniger Phagozyten zu bekämpfen. Auf Grund seiner experimentellen Untersuchungen war er zu der Überzeugung gekommen, dass die Verheilung des tuberkulösen Prozesses durch aktive Phagozytose zustande kommt. Er stellte sich die Aufgabe, das digestive Vermögen der mononukleären Zellen den Tuberkelbazillen gegenüber $\mathrm{zu}$ steigern und sie für den spezifischen Kampf mit den Tuberkelbazillen geeigneter zu machen, mit anderen Worten, er wollte durch Auslese aktiver tuberkulöser Antigene und passendster Arten von Tieren ein Serum darstellen, welches imstande war, einkernige Leukozyten zu aktivieren und sie für den spezifischen Kampf gegen die Tuberkulose vorzubereiten.

Von sämtlichen Tierarten hatten sich die Hunde am geeignetsten erwiesen. Die Immunisierung derselben erreichte er mittels eines nach der Methode von Besredka (6) hergestellten tuberkulösen Endotoxins. Der Impfstoff Besredkas ist eine Mischung einer Aufschwemmung von einer Bazillenkultur in physiologischer Kochsalzlösung mit dem Serum eines Tieres, das mit der betreffenden Bazillenart vorbehandelt war. Es tritt zunächst eine Agglutination und eine Bindung der Bazillen an die im Serum gebildeten Immunkörper ein. Der Überschuss des Serums wird durch Zentrifugierung und Auswaschung mit physiologischer Kochsalzlösung entfernt. Das zur Ausführung dieser Methode notwendige stark agglutinierende Serum erhielt Neporos chny von einem speziell präparierten Pferde. Nachdem die Hunde sich an beträchtliche Mengen dieses sensibilisierten Vakzins gewöhnt hatten, spritzte er ihnen zunächst entfettete Bazillenleiber, später mittels Chloroform abgetötete, nicht entfettete Bazillen in die Venen und die 
Peritonealhöhle ein. Sobald die Hunde auch diese Injektionen vertrugen, begann er die eigentliche Immunisierung, indem er ihnen lebende, in keiner Weise bearbeitete Tuberkelbazillen injizierte. Es unterscheidet sich demnach der von Neporoschny ausgeübte Immunisierungsmodus wesentlich von den Methoden Maraglianos und Marmoreks (s. unt.), die zur Herstellung ihrer Sera vor allem nie lebende Tuberkelbazillen injizierten.

Über die Heilerfolge von Meerschweinchen, insbesondere über die Heilungsform -wurde bereits oben berichtet. Ergänzend sei hinzugefügt, dass die bei Meerschweinchen beobachteten pathologischen Veränderungen solchen glichen, die auftreten, wenn man diese Tiere mit einer nicht tödlich wirkenden Dosis von Tuberkelbazillen impft.

Neporoschnys klinische Beobachtungen zeigten, dass bei den mit seinem Serum behandelten Patienten erst nach einigen Tagen eine Temperatursteigerung auftritt, eine Reaktion, deren Intensität von der eingespritzten Dosis und von dem Allgemeinzustand des Organismus abhängig ist. Diesem Umstande glaubt Neporoschny besonderen Wert beimessen zu können, indem er diese Temperatursteigerung in direktem Zusammenhang mit der durch das Serum bewirkten spezifischen Phagozytose bringt. $\mathrm{Ob}$ man dem so ganz beiptlichten darf, erscheint fraglich, denn diese Reaktion kann man, nach Pawlowsky (33), auch lediglich als eine Tuberkulinreaktion auffassen, da Neporoschnys Serum ein Endotoxinserum ist, dem man wohl mit gleichem Recht die Ursache dieser von ihm so hoch bewerteten Temperatursteigerung zuschreiben darf. Auch die Drüsenschwellungen, die erst bei erfolgreicher Serumbehandlung auftreten, dienten Neporoschny als Beweis für die Richtigkeit seiner Theorie der ,aktivierenden Wirkung auf die zytogenen Gewebe des Organismus". Über sonstige Ergebnisse bei Anwendung des Antituberkulose-Serum Nepor os chnys liegen von seiten anderer Autoren keine Veröffentlichungen vor.

Wohl das grösste Aufsehen erregten die Ausführungen über die Serotherapie der Tuberkulose, wie sie Marmorek (26) gab.

Ausgehend von der Tatsache, dass verschiedene tuberkulöse Individuen auf dieselbe Dosis von Koch schem Tuberkulin nicht in gleicher Weise reagierten, nämlich einerseits bei gesunden und andererseits bei solchen, die in mässigem Grade tuberkulös sind und endlich bei solchen, deren Organismus von Tuberkelbazillen geradezu überschwemmt ist, legte sich Marmorek die Frage vor: Ist das Tuberkulin mit jenem Gift zu identifizieren, das die Tuberkelbazillen sezernieren und durch dessen Gegenwart die spezifischen krankhaften Veränderungen im Organismus hervorgerufen werden. 
Marmoreks Ansicht nach ịst das Tuberkulin eine vorbereitende Substanz, ein Reagenz, das auf die im Organismus vorhandenen Tuberkelbazillen einwirkend diese anregt, ein ganz a nderes Gift reichlich abzusondern. Mit anderen Worten: Die bekannte Tuberkulinreaktion ist durch die Bildung eines Toxins verursacht, welches der Bazillus sezerniert, weil und nachdem das Tuberkulin mit ihm in Berührung gekommen ist. Hierdurch findet nach der Meinung Marmoreks die Erscheinung ihre Erklärung, dass durch diese spezifische Wirkung des Tuberkulins auf den Bazillus selbst der kleinste tuberkulöse Herd in eine Art intensiver Giftproduktion verwandelt wird und dadurch klinisch nachgewiesen werden kann. Weiter erklärt sich die Rolle des Tuberkulins, wenn man die beiden extremsten Fälle ins Auge fasst: Die gesunden Individuen und die schwer tuberkulösen Kranken. Bei beiden ist eine Reaktion auf Tuberkulingaben nicht zu konstatieren, im ersten Fall wegen der Abwesenheit der das Toxin sezernierenden Bazillen, im anderen Fall, dem der vorgeschrittenen Tuberkulose, sind die Bazillen mit ihrer überstarken Tätigkeit schon von Toxin getränkt und reagieren auf die relativ minimale Dosis von Tuberkulin nicht mehr, wenigstens nicht derart, dass die Reaktion klinisch nachweisbar wird. Von diesem Gesichtspunkte aus glaubt er, sind auch die "AntituberkuloseSera" aufzufassen, die in Wirklichkeit Antituberkulin-Sera sind, Sera, die durch Vorbehandlung von Tieren mittels Kochschem Tuberkulin gewonnen sind.

Marmoreks Gedankengang war nun der, dass das von ihm angenommene spezifische Toxin lediglich dann ausserhalb des Organismus und in vitro gebildet wird, wenn man den Tuberkelbazillus unter Bedingungen brächte, die möglichst jenen glichen, welche an dem gewöhnlichen Sitze des Toxins vorhanden sind.

Zur Erzeugung des Toxins schienen Marmorek junge Tuberkelbazillen - „Bacilles à type primitif" — mit ihrer sehr dünnen Wachsund Fetthülle besonders geeignet, die er mit einem leukozytären Serum in Berührung brachte. Ein leukozytäres Serum verwandte er deswegen, weil der Tuberkelbazillus auch in vivo im Inneren der Leukozyten oder, nachdem er jene verlassen hat, die von M. gesuchte Substanz bildet und absondert. Dieses Serum, von Marmorek "leukotoxisches Serum" genannt, gewann er dadureh, dass er Kälbern grosse Mengen von Meerschweinchen-Leukozyten injizierte.

Im Verlaufe seiner Untersuchungen fiel es Marmorek auf, dass die Leber einen gewissen Grad von Immunität gegenüber dem Eindringen der Tuberkelbazillen besitzt. Deshalb versuchte er, Tuberkelbazillen auf einem Nährboden zu züchten, den er aus Leber- 
substanz gewonnen hatte. Er wollte dadurch die Stoffwechselarbeit des Bazillus erhöhen und Hand in Hand damit seine toxinabsondernden Fähigkeiten steigern. Sobald sich der Tuberkelbazillus an diesen für sein Fortkommen wenig günstigen Nährboden gewöhnt hatte, wuchs er schneller und reicher als in den Kontrollkulturen und, worauf Marmorek besonderen Wert legte, blieb der so gezüchtete Bazillus länger "primitiv" und sollte ausserdem eine ganz besondere toxische Substanz in sich bergen, die dem Kochschen Tuberkulin jedenfalls nicht eigen wäre.

M armorek züchtete also die sogen. "Primitivbazillen" auf einem Nährboden, der aus leukotoxischem Serum und Extrakt von Lebergewebe bestand, und wollte dadurch eine Substanz gewinnen, der nach seiner Meinung eine erhöhte Virulenz zukam." Nun war seine Aufgabe zu beweisen, dass diese Substanz das von ihm gesuchte Toxin enthielt, mittels der er auch Tiere gegen spätere Bazilleninfektion immunisieren konnte. Durch Tierversuche kam er zu der Überzeugung, dass sein Toxin identisch wäre mit jenem, welches der Bazillus in dem Tuberkel erzeugte. Des weitern war es ihm gelungen, ein antitoxisches Serum zu gewinnen, indem er Pferde mit seinen Kulturen, die vorher filtriert wurden, immunisierte. Die Tiere reagierten auf die steigende Menge von Toxin sehr stark mit Temperatursteigerung bis zu $40^{\circ}$, grossen und schmerzhaften Ödemen und schlechtem Allgemeinbefinden.

Mit dem Serum der auf diese Weise vorbehandelten Pferde konnte er bei Meerschweinchen und Kaninchen, denen er 1--2 Tropfen einer schwach opaleszierenden Emulsion von virulenten Bazillen in die Ohrvene injiziert war, das Tuberkeltoxin neutralisieren; es übte nicht nur eine präventive, sondern auch eine kurative Wirkung aus. Geleitet von dem Gedanken, dass der Mensch weit wirksamere Verteidigungsmittel gegen die Tuberkulose besitzt als die Versuchstiere, nahm er an, dass sein Antituberkulose-Serum beim Menschen weit kräftiger wirken würde.

Marmoreks Versuche am Menschen erstreckten sich auf die verschiedensten Arten und Unterarten der Tuberkulose, teils auf Kranke mit solchen Läsionen, bei denen der gesamte Organismus stark affiziert war, infolge von ausgedehnten tuberkulösen Zerstörungen im Bereiche der Lungen und auf Kranke mit tuberkulöser Meningitis, teils auf solche mit lokaler chirurgischer Tuberkulose. Im Laufe der Behandlung kam er zu der Überzeugung, dass dem Alter der Erkrankung weit mehr Wichtigkeit beizulegen war, als der Ausdehnung der tuberkulösen Zerstörungen. Auch war er sich damals (1903) bewusst, dass die bei ausgedehnter Tuberkulose häufig 
bestehende Streptokokken-Mischinfektion die Prognose sehr verschlimmerte (darüber weiter unten),

Mit den Resultaten war Marmorek selbst zufrieden. In mehreren Fällen konnte er beobachten, dass Eiter, der sich in einem käsigen Herde befand, resorbiert wurde, Abszesse mit Fistelgängen trockneten ein und schlossen sich. Als Ort der subkutanen Einspritzung wurde von Marmorek zuerst die Bauchgegend empfohlen, doch ging er bald von dieser Applikationsstelle wieder ab, da sich die Einstichstelle oft als recht schmerzbaft erwies. Die Einspritzungen wurden deshalb an den Extremitäten vorgenommen. Doch auch bei dieser Art der Applikation zeigten sich, namentich wenn sie längere Zeit ohne Pausen vorgenommen wurden, unangenehme Nebenerscheinungen: Diese waren teils rein lokaler, teils mehr allgemeiner Natur und bestanden in Rötung und Schwellung der Umgebung der Injektionsstelle, bisweilen in grösserer Ausdehnung. Manchmal trat lokalisiertes, oft auch allgemeines Erythem auf, ebenso Urtikaria, bald leichteren, bald stärkeren Grades, Schmerzhaftigkeit der geschwollenen Partien, Gelenk- und Gliederschmerzen, Drüsenschwellungen. Als Allgemeinerscheinungen wurden Unruhe und allgemeines Unbehagen, Tachykardie, Kopfschmerzen, Erbrechen, Benommenheit beobachtet. Temperatursteigerungen stellten sich ein und die Pulszahl stieg bis auf 130 .

Man hat anfangs diese plötzlich auftretende Verschlimmerung des Krankheitsbildes falsch gedeutet und liess sich deswegen verleiten, den weiteren Gebrauch des Serums einzustellen.

Schon lange bevor der wissenschaftliche Beweis erbracht wurde, dass dies unrichtig sei, äusserten mehrere Autoren ihre Ansicht dahin, dass dies lediglich Reaktionserscheinungen des Organismus auf das artfremde Eiweiss (Pferdeserum) wären. Es handelte sich um die Erscheinung der Überempfindlichkeit oder Anaphylaxie, die bei der öfteren parenteralen Injektion von fremdalbuminoiden Stoffen auftritt. Diese anaphylaktischen Erscheinungen wurden durch die rektale Anwendung, in Form eines Einlaufes, vermieden. Auf diese Weise konnte man nun eine lang anhaltende Behandlung ohne welche Nebenwirkungen in die Wege leiten.

Eine nicht unwesentliche Verbesserung des Serums glaubte Marmorek dadurch herbeizuführen, dass er später ein sogen. ,Doppelserum" herstellte. Dazu veranlasste ihn der Umstand, dass namentlich bei der Lungentuberkulose so häufig noch eine StreptokokkenMischinfektion besteht. Er musste also ein ,Antituberkulose-Antistreptokokken-Serum" gewinnen. Dieses Serum erhielt er von Pferden, die einerseits in der angegebenen Weise gegen Tuberkulose und 
andererseits mindestens $2^{1 / 2}$ Jahr lang gegen eine grosse Zahl von Streptokokkenstämmen, die direkt aus dem Sputum Tuberkulöser rein gezüchtet wurden, immunisiert waren. Marm o rek glaubte dadurch Antitoxine gegen Streptokokken gewonnen zu haben, näher liegt es, sie als antibakterielle Substanzen im Sinne der Ehrlichschen Ambozeptoren aufzufassen (Köhler und Lenzmann) (21).

Seit dieser Zeit sollen die Erfolge günstiger geworden sein. Die Technik der rektalen Ergiessungen war eine recht einfache, mittels Nélaton-Katheter wurden 2-3 Wochen lang je 5 ccm eingeführt, worauf eine Ruhepause von 8 Tagen eintrat.

Die Literatur über das ,Serum-Marmorek" ist eine recht grosse. Die erste Sammlung der Veröffentlichungen über die Resultate bei der Anwendung dieses Serums nahm Monod, Paris (29), vor. Er konnte in einem Vortrage, den er in der medizinischen Akademie zu Paris hielt, über 38 Publikationen berichten, die sich mehr oder weniger in günstigem Sinne über die $\dot{M}$ armoreksche Methode ausdrückten. Sie bezogen sich auf im ganzen 592 Fälle von lokalisierter, chirurgischer und Lungen- sowie auch allgemeiner Tuberkulose. Monod fasste sein Urteil über diese Arbeiten etwa in folgenden Sä.tzen zusammen:

1. Die Anwendung des antituberkulösen Serums von Marmorek ist absolut unschädlich.

2. Die Wirkung des Serums zeigt sich bei allen Formen der Tuberkulose, bei der Tuberkulose der Lungen, der Gelenke, der Knochen usw.

3. Diese Wirkung erstreckt sich bei der Tuberkulose der Lungen auf die funktionellen wie physikalischen Symptome; auf Schmerz, Eiterung, Fisteln und anatomisch-patbologischen Veränderungen bei chirurgischer Tuberkulose.

4. In einer grossen Zahl der behandelten Fälle war die Wirkung derartig, dass alle Krankheitssymptome verschwanden, so dass man von einer "Heilung" sprechen konnte. Diese Fälle von Heilung fanden sich oft bei chirurgischer Tuberkulose, bei Lungentuberkulose war dagegen eine bedeutende Besserung eingetreten.

Den erwähnten 38 Veröffentlichungen standen 5 gegenüber, die nur Ungünstiges über das Marmorek-Serum berichteten Von diesen seien hier die Ergebnisse von Krokiewicz und Engländer (23) und Guido Mann (24) kurz mitgeteilt: Die beiden ersten Autoren behandelten mit dem Serum Marmorek 8 Fälle von Lungenphthise und zwar in allen 3 Stadien. Unter allen Kautelen der strengsten Aseptik injizierten sie $10 \mathrm{ccm}$ in das subkutane Zellgewebe der Bauchdecken. Die therapeutische Wirkung stellte sich als eine nicht- 
günstige dar. Anfangs war hie und da die Wirkung günstig, doch später trạt dauernde Verschlimmerung ein; vor allem konstatierten sie einen ungünstigen Einfluss des Serums auf den Verlauf der Temperatur.

Guido Mann (24) wandte das Serum rektal an, und zwar 21 Tage 5 ccm pro die, dann eine Woche Pause. 23 Fälle wurden so behandelt; er kommt zu dem Schluss, dass das Resultat bei der Anwendung des Marmorekschen Serums als absolut negativ zu bezeichnen ist. Die Sektion, die bei 5 vorgenommen wurde, ergab, dass ,fast kein Millimeter Gewebe der Lungenoberfläche von Tuberkeln frei geblieben war" (!). Diese und andere pathologischen Befunde erweckten den Eindruck, als ob das Serum dem Zerstörungsprozess der Tuberkelbazillen Vorschub geleistet hätte.

Die ungünstigen Resultate, die Krokiewicz und Engländer (23) hatten, beruhen wohl auf eingetretener Anaphylaxie, nach subkutaner Injektion. Denn erst nach längerer Anwendung traten erhöhte Temperaturen usw. auf, während sie zu Anfang eine günstige Beeinflussung durch das Serum beobachteten Dasselbe gilt wohl für die von W. Hol mboe (17) (Norwegen) allerdings später publizierten sehr ungünstigen Resultate der Anwendung des Serum M armorek. Denn Holmboes Erfahrungen beziehen sich auch nur auf die subkutane Anwendung des Serums, über die rektale hat er keine Erfahrungen, wie er selbst in seiner Veröffentlichung bemerkt.

Holmboe (17) injizierte in Intervallen, wie sie oben angegeben wurden; er beobachtete ausser unwesentlichen Komplikationen in 4 Fäjlen plötzlich auftretende, gefahrdrohende Kollapszustände. Dass diese infolge von einer übrigens nicht bezweckten intravenösen statt subkutanen Injektion auftraten, will $\mathrm{Holmboe}$ nicht absolut verneinen. Denn es war ihm aufgefallen, dass bei den erwähnten Fällen reichlich Blut aus dem Stichkanal floss, nachdem er die Spritze herausgezogen hatte. Auch $\mathrm{Hol}$ moe hatte beobachtet und bezeichnete es als auffallend, dass keiner von den 4 unangenehmen Vorfällen vor der 10. Injektion eintrat. Man darf daraus wohl schliessen, dass es sich auch hier um eiweiss-anaphylaktische Nebenerscheinungen handelte, die allerdings in den betreffenden Fällen in ganz ungewöhnlicher Form in die Erscheinung traten.

Wie bereits oben erwähnt, ist die Anaphylaxie durch die rektale Anwendung leicht zu vermeiden und die Wirkung des Serums soll nach Ansicht vieler Autoren dieselbe bleiben, wenngleich wir über die Gesetzmässigkeit der Resorption im Darm für das Marmoreksche Serum nichts wissen.

Was nun die Beobachtungen Manns (24) angeht, der die hoch- 
gradigen pathologischen Veränderungen in der Lunge zu Gesicht bekam, so kann man gerechterweise diese Befunde nicht allein dem Serum zuschreiben; näher liegt es, dass bereits beim Beginn dex Kur dieser ausgedehnte Zerstörungsprozess in den Lungen bestanden hat, und es sich demnach um sehr progressive Fälle von Lungenphthise handelte. Vielleicht hat dieser Autor auch insofern einen Fehler in der Anwendungsmethode gemacht, als er die einzelnen Fälle zu wenig individualisierte: allen 23 Fällen hat er ohne Rücksicht auf ihr Stadium dasselbe Quantum Serum 21 Tage lang rektal injiziert. Vor einem derartigen Schematismus warnten später Wein (42) und Frey (11).

Wein (42), der bei seinen mit Serum Marmorek behandelten Patienten $30 \%$ Heilung und bei den übrigen, nicht Geheilten, 96\% günstige Beeinflussung eintreten sah, sagt, dass die "hervorragende spezifische Wirkung “ des Serums in der Unschädlichmachung der von den Tuberkelbazillen gebildeten Gifte bestände. Als Folge dieser Entgiftung trete eine ,automatische lokale Reaktion" (!) ein, die übermässig anschwellend auch schädlich wirken könnte.

Diese Ansicht W eins von einer eventuell eintretenden Schädlichkeit des Serums ist wohl so aufzufassen, dass das Serum als ein antitoxisches Serum in übergrossen Dosen gereicht auf den Organismus dadurch schädigend wirken kann, dass ein Teil desselben im Körper unverbraucht bleibt.

Andererseits machte derselbe Autor später die Beobachtung, dass bei der Hälfte der mit dem Serum behandelten Patienten im Verlaufe der Behandlung bis dahin nicht beachtete Erkrankungsherde sinnfällig wurden. Das Serum bewirkte also eine Aktivierung der in der Tiefe gelegenen, abgekapselten tuberkulösen Herde, wodurch diese zum Ort mehr oder weniger mächtiger Entzündungsvorgänge wurden, die ihrerseits wieder, namentlich bei sehr veralteter und ausgedehnter Tuberkulose, grosse Gefahren für den Gesamt-Organismus in sich bergen können. - Wenn dem so ist, so haben wir zum mindesten kein rein antitoxisches Serum vor uns. - Um also einer unter solchen Umständen bestehenden Intoxikationsgefahr wirksam zu begegnen, ist eine sorgfältige Individualisierung in der Darreichung des Serums unbedingt erforderlich. Doch diese ist wieder infolge der ungleichmässigen Darmresorption erschwert, denn es fehlt uns bei den rektalen Ergiessungen an Mitteln, die Dosierung dem individuellen Charakter des einzelnen Falles anzupassen.

Eine sehr umfangreiche Sammlung der Veröffentlichungen über das Marmoreksche Serum nahm 1908 Frey, Davos (11), vor. Da ihm fast die gesamte, bis zu diesem Zeitpunkt erschienene Literatur 
zu Gebote stand, so ist dieser Zusammenstellung unbedingt Wert beizumessen. Frey lagen die Arbeiten von 70 Autoren vor, von diesen kommen nur 11 zu negativen Resultaten. Nach der Freyschen Statistik betrug die Gesamtzahl der behandelten Fälle 938, davon waren 662 Fälle mit Lungen- und Kehlkopf-Tuberkulose, 239 mit chirurgischer Tuberkulose und 33 Fälle mit tuberkulösen and skrofulösen Augenerkrankungen. Von der Gruppe I wurden günstig beeinflusst bis geheilt $64 \%$, unbeeinflusst, verschlechtert oder gestorben $36 \%$; von Gruppe II wurden $79 \%$ günstig beeinflusst bis geheilt. Das günstigste statistische Resultat ergaben, die Augenerkrankungen, Heilung trat allein in $60 \%$ der Fälle ein, wesentliche und teilweise Besserung bei $31 \%$, kein Einfluss oder Verschlechterung bei $9 \%$.

Frey glaubt auf Grund dieser Statistik, die sich auf Kranke mit schweren und progressiven Prozessen bezieht, die selbst durch die sonstigen diätetisch-hygienischen Massregeln unbeeinflusst blieben, die günstige Beeinflussung dem Marmorek-Serum zuschreiben zu können.

Im folgenden soll auf die Publikationen einzelner Autoren, die zum Teil auch der Freyschen Statistik zugrunde lagen, näher eingegangen werden, um so mehr, da Frey darauf in seiner Arbeit im einzelnen nicht eingehen konnte. Ferner sollen die Veröffentlichungen nur derjenigen Autoren erwähnt werden, die das Serum rektal zur Anwendung brachten, deren Beobachtungen also nicht durch anaphylaktische Nebenerscheinungen beeinträchtigt wurden.

Von den eben erwähnten 11 Autoren, die zu negativen Resultaten kamen, hatten allein 6 Autoren, wie wir aus der uns vorliegenden Literatur ersehen konnten, das Serum subkutan angewandt; 4 bedienten sich der rektalen Applikation, es waren dies Sievers (36), Mann (24), E. Bock-Laibach (7) und Hohmeyer-Altona (16). Ausser diesen sahen noch 3 andere Autoren, die erst später ihre Resultate publizierten, keine spezifische günstige Beeinflussung eintreten, Gangh ofner-Prag (12) und Grüner-Wien (14).

Ho h m e y e $r(16)$ behandelte mit dem Serum Fälle von chirurgischer Tuberkulose. Bei ganz leichten Fällen von Knochentuberkulose hält er eine Beschleunigung des Heilungsprozesses dann für möglich, wenn man gleichzeitig eine antituberkulöse Kur einleitet. Bei mittelschweren Fällen erzielte er keinerlei Erfolge, und bei schweren Fällen sah er noch nicht mal Besserung eintreten.

Gangh of $n$ er (12), der mit dem Serum 9 an chirurgischer Tuberkulose leidende Kinder behandelte, sah nennenswerte Heilerfolge, die er allein auf eine spezifische Wirkung des Serums hätte zurückführen können, nicht. Auch scheint es ihm zweifelhaft, ob die in dem Anti- 
tuberkulose-Serum supponierten Antitoxine durch die rektale Applikation in unverändert wirksamem Zustande zur Resorption gelangen.

Grüner (14) resumiert seine Erfahrungen dahin, dass das Serum weder bei Lungen- noch bei Knochentuberkulose im Kindesalter eine zuverlässige Heilwirkung entfaltet, dass ferner das Serum Marmorek auch bei lang dauernder Anwendung nicht imstande sei, das Auftreten frischer Krankheitsherde zu verhindern. Der Allgemeinzustand wird nicht günstig beeinflusst. Nach seinen Versuchen ist das Serum in hundertfacher Menge nicht imstande, die Kutanreaktion auf Tuberkulin aufzuheben oder abzuschwächen.

Ebenso konnten sich Pfeiffer und Trunk (34) von dem Fehlen einer Abschwächung des Tuberkulins durch das Antituberkuloseserum überzeugen; die von ihnen mit dem Serum behandelten Kranken (52 im ganzen) gaben die von Pirquetsche Kutan- wie auch OphthalmoReaktion. Ob dies einen. Schluss auf den antitoxischen Wert des Präparates zulässt, erscheint den Autoren nach dem heutigen Stande der Diskussion über diese Reaktion nicht sicher.

Von Bock-Laibach (7) wurden 8 Fälle skrofulöser Augenleiden bei Kindern mit dem Serum Marmorek behandelt. In 2 Fällen gingen die Entzündungserscheinungen zurück, doch die Hornhauttrübungen blieben bestehen. Die übrigen 6 Fälle wurden überhaupt nicht beeinflusst, im Gegenteil, in 2 von diesen traten direkt örtliche Verschlimmerungen auf. Da sich ausserdem noch mancherlei Schädigungen des Allgemeinbefindens einstellten, wie Mattigkeit, Kopfschmerzen, Fieber, Durchfälle u. a., nahm Bock schon nach höchstens 8 Einspritzungen von der Weiterbehandlung mit dem Serum Abstand.

Um nun gleich bei der Behandlung skrofulöser und ähnlicher Augenleiden mittels Marmorekschen Serum zu bleiben, sollen die diesbezüglichen Resultate zweier Autoren erwähnt werden, deren Erfolge immerhin als günstig zu bezeichnen sind, Schwartz (38) und Ullmann (39). Wenngleich Schwartz nur Gelegenheit hatte, einen Fall einer Conjunctivitis bulbi tuberculosa mit dem Serum Marmorek zu behandeln, so ist die Wirkung des Serums so eklatant, dass mit einigen Worten auf seine Mitteilung eingegangen werden soll. Schwartz behandelte mit dem Serum einen Fall von einer zweifellos tuberkulösen Augenerkrankung, die bereits die ganze Conjunctiva bulbi ergriffen hatte, sie war in der gesamten Ausdehnung von einer Anzahl gelber eitriger Infiltrate durchsetzt. Während sonst bei derartigen ausgedehnten Konjunktivalerkrankungen das Auge meist geopfert werden muss, erzielte Schwartz nach 37 Injektionen (jeden 2. Tag $5 \mathrm{ccm}$ subkutan) eine vollständige 
Heilung. Auch er bemerkte bereits nach der 3. Injektion ein Schwinden der zahireichen Infiltrate, die nach Injektionen von $49 \mathrm{ccm}$ völlig verschwunden waren. Fieber ist bei seinen Patienten nie aufgetreten, auch das Allgemeinbefinden. war während der ganzen Dauer der Kur ununterbrochen ein vorzügliches. Die Sehschärfe des erkrankten Auges wurde wieder normal, desgl. der Augenspiegelbefund. Schw a r tz hält die Wirksamkeit des Serums für spezifisch and unzweifelhaft.

Ullmann (39) hat im Verlauf von 2-3 Jahren 20 Fälle von skrofulösen und tuberkulösen Augenerkrankungen desgleichen mit dem Serum behandelt, es waren in der Mehrzahl jugendliche Patienten. Nachdem die übliche medikamentöse Behandlung (Atropin und Kalomel) ausserhalb der Klinik ohne Erfolg geblieben waren, wurden in der Klinik rektale Injektionen des Marmorek-Serum vorgenommen. Schon nach dem 3. Klysma wurden die Lichtscheu und die Trübungen der Hornhaut geringer, und nach weiterer Verabreichung des Serums trat in den meisten Fällen vollkommene Heilung ein, wenn auch in dem ein oder anderen, allerdings veralteten Fall, kaum sichtbare Trübungen auf der Kornea zurückblieben. Rezidive sah Ullmann nach erfolgreicher Serumbehandlung selbst nach 2 Jahren nicht auftreten. Auch hat er nie diese schweren Störungen im Allgemeinbefinden beobachtet, wie sie von Bock (7) beschrieben wurden. U11man $n$ betont jedoch, dass man in den meisten Fällen von skrofulösen Keratitiden nur dann mit einem Heilerfolg rechnen könnte, wenn die Serumbehandlung gleich zu Beginn der Augenerkrankung einsetze, und die Makulae in der Kornea noch nicht ausgedehnterer und tiefgreifenderer Natur wären.

Gerade über diese beiden, vielleicht nicht unwesentlichen Punkte findet man in den von Bock (7) beschriebenen Krankheitsfällen nichts angegeben. Der Grund seiner Misserfolge ist wohl dem Umstande zuzuschreiben, dass man bei den Patienten, nachdem sie in die Klinik aufgenommen waren, oft noch 6-8 Wochen verstreichen liess, bevor zur Serumbehandlung gegriffen wurde.

Wenn die Erfahrungen mit dem Serum Marmorek bei den erwähnten Augenerkrankungen noch recht minimal sind, so sind sie ungleich grösser bei der chirurgischen Form der Tuberkulose.

Den berichteten ungünstigen Resultaten steht eine grosse Zahl von Publikationen gegenüber, deren Autoren günstiger über das Serum urteilen. Auf die sämtlichen Arbeiten im einzelnen und des näheren einzugehen, erübrigt wohl. Es sollen lediglich diejenigen Publikationen Erwähnung finden, deren Autoren sich im Laufe von Jabren und an zahlreichem Krankenmaterial eine möglichst objektive Meinung über das Serum Marmorek bilden konnten. 
In Deutschland fand zum erstenmal in der Verhandlung der Berliner klinjschen Gesellschaft, 1907 (43), eine öffentliche Diskussion über das nene Heilmittel Marmoreks statt.

Van Huellen (18) konnte über Exfahrungen berichten, die er zusammen mit Sonnenburg im Krankenhaus Moabit mit dem Antituberkulose-Serum Marmorek gemacht hatte. Er bestätigte, dass seit der rektalen Applikation keine anaphylaktischen Erscheinungen mehr aufgetreten seien. Das Allgemeinbefinden der Patienten hätte sich sowohl in somatischer als auch psychischer Hinsicht gehoben; häufig konnte er beobachten, dass die Schmerzen nachliessen. Behandelt wurden Fälle mit chir urg is cher Tuberkulose. Die Sekretion aus tuberkulösen Fisteln liess nach, die Fisteln versiegten, wurden kleiner und schlossen sich; glasige Granulationen schrumpften and wurden von gesunder Haut überwachsen. Allerdings war bei diesen günstig verlaufenden Fällen die Behandlung eine kombinierte (Sequestrotomie und Einspritzung von Jodoformglyzerin). Verschlimmerung der Symptome hat van $\mathrm{Huellen}$ bei der Anwendung des Serums niemals gesehen.

Hoffas (15) Erfahrungen erstreckten sich auf einen Zeitraum von 3 Jahren. Er behandelte damit Tuberkulose der Knochen und Gelenke. Er ist zu der Überzeugung gekommen, dass dem Marmorek-Serum durchaus ein günstiger und geradezu spezifischer Einfluss auf die Ausheilung der Knochen- und Gelenk-Tuberkulose zuzuschreiben ist, obschon bei konservativer Behandlung eine grosse Anzahl von diesen Erkrankungen auch ohne Anwendung des Serums heilen könnten. Doch hat er Fälle beobachtet, bei denen die günstige Einwirkung des Heilmittels verblüffend war, so z. B. bei einem Kinde mit einer Spondylitis tuberculosa mit Senkungsabszessen bis in beide Beine, bei dem eine 3 jährige Behandlung keine Besserung bewirkt hatte, verschwand die Parese der Beine bereits nach 12 SerumEinspritzungen, und nach weiteren Injektionen war Pat. vollständig ausgeheilt. Die gleichen günstigen Resultate hatte $\mathrm{H}$ off a auch bei einem Kinde mit multipler Tuberkulose: nach 96 Serumeinspritzungen war der günstige Einfluss absolut unverkennbar. Auch dieses Kind war vordem 3 Jahre lang vergebens in seiner Klinik behandelt worden.

Trotz dieser guten Erfahrungen, die Hoffa (15) mit dem Serum Marmorek gemacht hat, steht er auf dem Standpunkt, dass das Serum nicht unser alleiniges Hilfsmittel sein darf, sondern als Adjuvans neben den anderen anzuwenden ist.

Nach einer später von ihm veröffentlichten Statistik fasst er seine Erfahrungen wie folgt zusammen: Keine Besserung in $18 \%$, Besserung in $36 \%$, grosse Besserung in $37 \%$ und Heilung in $18 \%$. 
Über ähnliche gute Erfolge bei chirurgischer Tuberkulose konnte Glaessner (13) berichten. Die günstigsten Resultate konnte er namentlich bei frischen Fällen von chirurgischer Tuberkulose verzeichnen. Das Allgemeinbefinden und der Appetit besserten sich schnell; schon nach wenigen Einspritzungen begannen stark absondernde Fisteln auszutrocknen, und Geschwürsbildungen gingen zurück, auch alte, hartnäckige Fälle wurden erheblich gebessert. Das Serum erwies sich als wesentliche Unterstützung der übrigen Behandlungsmassnahmen.

Wein-Ofenpest (42), der gleichfalls mehrjährige Erfahrungen, namentlich in der Behandlung chirurgischer Tuberkulose mit dem M a r m o r e k - Serum hat, berichtete 1909 über 59 tuberkulöse Kranke, die er mit dem Serum behandelte. 53 von diesen, die bis zu 205 Einspritzungen erhielten, wurden 34 gut gebessert und 18 als geheilt entlassen, 1 Patient starb. Wein hält das MarmorekSerum für ein "hervorragendes spezifisches Heilmittel" der Tuberkulose, das auch diagnostisch verwertbar ist.

Bei der Behandlung der Lungentuberkulose waren die Erfolge mit Marmorek-Serum teilweise wenig günstig, und seine Wirkung erscheint danach eine recht ungleiche zu sein. Auch hierüber liegen sehr zahlreiche Veröffentlichungen vor, von denen hier nur diejenigen angeführt werden sollen, die sich auf die monatelangen Beobachtungen, wie sie in Heilstätten möglich sind, beziehen.

B. H. Vos (41) wandte in einer Lungenheilstätte $\mathrm{Hollands}$ bei $2 \breve{b}$ seiner Patienten das Serum an, und zwar gehörten von diesen 6 dem I., 6 dem II. und 13 dem III. Stadium (T u rban-Gerhardt) an. Fast ausschliesslich handelte es sich um Fälle, die als schwerere zu bezeichnen waren; die ungünstige Beurteilung stützte sich auf den schweren Lungenbefund, auf das auch bei fortwährender Bettruhe anhaltende Fieber, oder auf den Umstand, dass bei der üblichen Behandlung, einschliesslich Tuberkulinbehandlung, weder der Allgemeinzustand noch der Appetit sich besserten.

Vos (41) wandte das Serum lediglich rektal an, 20 Tage hintereinander je $5 \mathrm{ccm}$, darauf 10 Tage Pause. Keiner seiner Kranken hat nach der Einverleibung irgend eine auf die Wirkung des Serums zurückzuführende Nebenerscheinung gehabt. Das Gesamt-Resultat war, dass von den 25 Patienten 7 günstig beeinflusst wurden. Von den Krankengeschichten sei hier eine mitgeteilt, die von Vos zu denen gerechnet wird, wo ein Erfolg nach der Serumbehandlung eingetreten war:

16 jähriger Tischler, seit 2 Jahren krank, Fieber, Nachtschweiss, Hämoptoe, Sputum tuberkelbazillenhaltig. 
Lungenbefund: Der Perkussionsschall war über der ganzen rechten Lunge tympanitisch gedämpft, in der oberen Hälfte war das Atemgeräusch vesikobronchial mit reichlich Rasselgeräuschen. L. war der Perkussionsschall über der Spitze gedämpft. Vorne vesikobronchiales Atmen und Rasseln bis zur IV. Rippe. Der Allgemeinzustand war leidlich gut. Körpergewicht 47,9 kg. Temperatur 36,5; Puls 100; Appetit gut.

Dieser Patient erhielt 135 Eingiessungen. Während der Behandlung besserten sich die Lungenerscheinungen allmählich. Bei der Entlassung (Pat. war 91/2 Monat in der Heilstätte) war bis zur 9. Rippe nichts Abnormes mehr zu hören. Das Allgemeinbefinden war erheblich besser als zu Anfang, keine Temperaturen mehr, das Gewicht hatte um $8,5 \mathrm{~kg}$ zugenommen. Pat. war wieder erwerbsfähig.

Vos zieht aus seinen Beobachtungen den Schluss, dass es sich lohnt, das Marmorek-Serum in sehwierigen Fällen zu versuchen, weil es unter Umständen Gutes leistet.

Unter den deutschen Autoren verdiente ganz besondere Frwähnung Köhler-Holsterhausen (20). Er hat sich zweimal über seine Erfahrungen mit dem Serum Marmorek geäussert und seine Untersuchungen und die sehr wesentlichen Nachuntersuchungen (nach 2 Jahren) sehr intensiv angestellt; auch verfügt er über ein Material (60 Fälle), das sicher einen gewissen Schluss erlaubt. Er resümiert in seiner letzten Arbeit, 1910, die den Abschluss über eine 2 jährige Beobachtung enthält, folgendermassen:

"Von den 60 mit. dem Marmorek-Serum behandelten Fällen waren nach 2 Jahren: 33 tot, 7 waren arbeitsunfähig, 9 hatten mit häufigen Unterbrechungen gearbeitet, 5 hatten mit kurzer Unterbrechung gearbeitet und waren gegenwärtig voll arbeitsfähig, 6 hatten ständig gearbeitet. Man kann somit sagen, dass 40 gänzliche Misserfolge, 9 teilweise Misserfolge and 11 zufriedenstellende Erfolge bei den Ersatzkontrollen nach 2 Jahren festzustellen waren.

Das Ergebnis ist im ganzen nicht sonderlich zufriedenstellend und muss das Serum Marmorek nicht als hervorragend wirksam charakterisieren. Von irgend welcher angenehmen Überraschung kann nicht die Rede sein, vielmehr erhält mein zurückhaltendes Urteil über das Serum, wie ich es in der Arbeit von 1908 vertrat, eine neue Stütze."

Auch hier wollen wir 2 von den von $\mathrm{K} \ddot{\text { oh }}$ ler berichteten Krankengeschichten mitteilen, aus denen hervorgeht, wie weit sich die Besserung bei Patienten vollzogen hatte, die mit Erfolg behandelt wurden:

33 jähriger Mann, Dauer der Kur 89 Tage. Keine Belastung, 
9. Kind. Seit 1/2 Jahr Nachtschweisse, Abmagerung, Blutspucken vor 3 Monaten, zeitweise Atemnot.

Befund: R. Clav. und R. Scap. verkürzt.

R. Clav.: Leise Atmung. Unterhalb abgeschwächte Atmung. Insp. abgesetzt bis IV. Rippe, von da ab reichliches Rasseln, feucht, auch in der A. L.

L. Clav.: Halbfeuchtes kleinblasiges Rasseln. Unterhalb Atmung rauh bis III. Rippe.

A. L.: Sehr unreines Insp. L. Scap.: Unreine Atmung im oberen Teil. Halbfeuchtes kleinblasiges Rasseln im unteren Teil, auch abwärts. R. Scap.: Unreine Atmung. Rhonchi angedeutet im oberen Teil. Abwärts unreine Atmung.

Tbac.: Negativ. Gewicht: $63 \mathrm{~kg}$, kein Fieber. Bei der Entlassung: Wenig Husten, noch viel Auswurf, zeitweise Schmerzen in der linken Seite.

R. Clav. und R. Scap. wenig verkürzt. R. Clav.: Vereinzelte kleinblasige trockene Geräusche. L. Clav.: Geringes Knacken im Exspirium. L. Scap.: Rauhes, unreines Insp. im oberen Teil. R. Scap.: Leichte Rauhigkeit im Insp. im oberen Teil.

Der Patient erhielt $200 \mathrm{ccm}$ Serum Marmorek per anum. Erfolg: Deutliche Besserung des Lungenbefundes bei geringer Hebung des Gewichtes, des Allgemeinzustandes und der subjektiven Beschwerden.

Die Nachuntersuchung nach 2 Jahren ergab, dass Patient ständig gearbeitet hatte. Wenig Husten und Auswurf. Einmal Blutspucken, keine Kur. Kontrollresultat: Günstiger Da u ererfolg.

Eine andere Krankengeschichte lautet: 25 jähriger Mann, der 74 Tage in der Heilstätte behandelt wurde. Keine Belastung. Vor einigen Monaten starke Erkältung, Husten. Allmähliche Abmagerung, kein Blutspucken, zeitweise Nachtschweisse.

Befund: R. Clav. und Scap. verkürzt. R. Clav.: Unreine Atmung bis II. Rippe, trockenes Rasseln bis III. Rippe. L. Clav.: Trockenes Rasseln. Unterhalb diffus rauhe Atmung. L. Scap.: Trockenes Rasseln, unterhalb rauhe Atmung. R. Scap.: Reichlich trockenes Rasseln, auch unterhalb vereinzelt. Bei der Entlassung: Kein Husten, kein Auswurf. L. Clav. und obere L. Scap. verkürzt. R. Clav.: Geringe Unreinheit im Exspirium. Unterhalb frei. L. Clav.: Frei. Abwärts: Frei. L. Scap.: Leicht rauhes Atmen, abwärts frei. R. Scap.: Frei, abwärts: Frei.

Bei der Aufnahme waren Tuberkelbazillen im Sputum. Gewicht: $65,5 \mathrm{~kg}$. Kein Fieber. Bei der Entlassung: Tuberkelbazillen: Negativ. Gewicht: $68,5 \mathrm{~kg}$. Kein Fieber. 
Die Nachuntersuchung nach 2 Jahren ergab: Ständig gearbeitet. Keine Kur. Kein Blutspucken. Kein Husten. Kein Auswurf. Gewicht: $68 \mathrm{~kg}$. Kontrollresultat: Durchaus günstiger Erfolg.

Im vorstehenden haben wir uns bemüht, in kritischer Weise die Arbeiten zu referieren, die über die Sero-Therapie der 'Tuberkulose handeln. Wir haben wohl fast vollständig die Autoren zu Wort kommen lassen, die sich tierexperimentell wie vor allem klinisch mit dem therapeutischen Vorgehen befasst haben, wie es ron Maragliano, Neporoschny und $\mathrm{M}$ armorek inauguriert wurde. Diese 3 Autoren stellen wohl die Hauptvertreter dieser therapeutischen Richtung der passiven Immunisierung im Kampfe gegen die Tuberkulose dar.

Betrachtet man nun aber dieses therapeutische Vorgehen, mit Hilfe artfremder Sera Antikörper gegen die Tuberkulose den erkrankten Menschen zuzuführen, also eine passive Immunisierung zu treiben, so ist zunächst die Frage zu beantworten: Was wissen wir überhaupt über Antituberkuline und sonstige tuberkulöse Antikörper, speziell über ihre Beziehungen zu den Heilungsprozessen bei den verschiedenen Formen der menschlichen Tuberkulose? Die noch nicht sehr zahlreichen Meinungen gehen heutzutage noch auseinander. Von Wichtigkeit erscheinen uns hier, wo wir die ganze Frage nicht erschöpfend behandeln können, die systematischen Untersuchungen von Bauer und Engel (2) über den Antituberkulingehalt bei tuberkulösen Säuglingen, die mit hohen Dosen von Kochschem Tuberkulin behandelt wurden. Diese Forscher können auf Grund ihrer ausgedehnten parallel laufenden serologischen und klinischen Untersuchungen sagen, dass zwischen Heilungstendenz und Höhe des Antituberkulin-Titers im Blute ein gewisser Parallelismus besteht. Bauer geht nunmehr auf Grund seiner hierbei gemachten Erfahrungen so weit, dass er so lange in der Steigerung der Tuberkulindosen fortfährt, bis ein hoher Antituberkulin-Titer im Blute nachzuweisen ist. Diese durch aktive Immunisierung beim Säugling erzielten Resultate beweisen noch lange nicht, dass wir in den Antituberkulinen den heilsamen Faktor zu sehen haben. Gesetzt den Fall, er wäre es, so ist damit a priori nicht gesagt, dass im gesunden oder kranken Tierorganismus gewonnene Antituberkuline bei Übertragung auf den Menschen heilsam wirken können. Solche Fragen lassen sich jedoch nur experimentell erledigen, wenn auch theoretisch manches gegen die Möglichkeit einer heilsamen Wirkung spricht.

Geben uns nun hierauf die vorliegenden Beobachtungen eine Antwort? Hier müssen wir wiederum kritisieren, dass wir trotz 
spitzfindiger theoretischer Erörterungen und verschiedener tierexperimenteller Untersuchungen exakte Angaben über den Gehalt an Antikörpern in den Tierseris vermissen. Wir können uns hier jedoch auf genaue Untersuchungen Bau ers (2) stätzen, der im MarmorekSerum keine Spur von Antituberkulin nachweisen konnte. Es wäre ja immerhin möglich, dass bei der komplizierten Darstellungsweise der Sera, dem langen Lagern usw. der Antikörpergehalt leidet, und dass andere Antikörper als das Antituberkulin in Betracht kämen.

Bei dieser Unsicherheit der Grurdlage sind diese Dinge recht schwer zu beurteilen, wenn uns auch so genaue klinische Beobachtungen, wie sie Köhler (20) und auch andere mitteilen, mahnen, deswegen noch nicht über das ganze Prinzip den Stab zu brechen.

Man darf auch nicht vergessen, dass solche therapeutischen Beeinflussungen nur dann einen Erfolg haben. können, wenn sie lange angewandt werden. Damit fallen selbstverständlich eine ganze Reihe von Formen der Tuberkulose sowohl der lokalisierten chirurgischen wie auch der Lungentuberkulose als Versuchsobjekte aus, und bei den Tuberkulosen, die dann noch der Untersuchung in dieser Richtung übrig bleiben, braucht man bekanntlich nicht jede Besserung auf das in der Zeit eingeschlagene therapeutische Vorgehen allein zu schieben.

Wir brauchen wohl nicht mehr weiter auszuführen, wie veränderte Lebensweise, Ruhe usw. in den Heilanstalten u. a. schon allein günstig wirken können, und die meisten derartigen Beobachtungen werden ja in Heilstätten und in Kliniken gemacht.

So müssen wir also hoffen, dass weitere Untersuchungen uns eine wissenschaftliche Grundlage für klinische Untersuchungen der passiven Immunisierung gegen Tuberkulose geben werden. Die vorliegenden Beobachtungen verlieren dadurch nicht ihren Wert.

Unter dem Gesichtspunkt, dass wir auch heute noch in der ätiotropen Behandlung der Tuberkulose nur wenig besser gestellt sind wie vor 20 Jahren, sind alle Versuche, in dieser Richtung einen Schritt weiter zu kommen, berechtigt, nur müssen sie mit der nötigen wissenschaftlichen Grundlage versehen und mit der nötigen Kritik jahrelang am Krankenbett ausprobiert werden.

Wir dürfen nicht vergessen, dass wir uns vielleicht mit der $\mathrm{Tu}$ berkulin- und Antituberkulin-Therapie auf einer ganz falschen Fährte befinden. Der Ausbau der Chemo-Therapie, die uns schon, um mit Ehrlich zu sprechen, so manche, ,parasitotrope Kugel gegossen hat", lässt uns vielleicht auch einiges für die zukünftige TuberkuloseTherapie erhoffen. 


\section{Literatur.}

1. B a bes, Essais de traitement de la tuberculose par l'injection du sérum de chiens rendu refractaires à cette maladie. Communication au Congrès poir l'étude de la tuberculeuse, 1893.

2. B a u r und Engel, Sonderd̈ruck ans: „Beiträge der Tuberkulose“" von Bra uer, XIII. Bd., Feft 3. Klin. und experimentelle Studien der Pathologie und Therapie der Tuberkulose im Kindesalter.

3. B e rnheim, Die Behandlung der Tuberkulose mit immunisiertem Serum. Mitteilung a. d. XI. Internat. med. Kongr. in Rom. Zentralbl. für Bakteriol. Bd. XV. 1894. S. 654.

4. Bertin und Picq, Immunität durch Transfusion von Ziegenblut bei Behandlung von Tuberkulose. Compt. rend. de la soc. de biologie. 1890. S. 719 .

5. Brancaceio, F. und A. Solaro, Therapeutische Untersuchungen über die 'Wirkung des Hundeserums bei Lungentuberkulose. Gl.' Incurabili 1893. S. 377 u. 341.

6. B e sredka, Annales de l'Institut Pasteur 1906, Die ud onné, 1911.

7. B $\circ \mathrm{ck}$, E. (Laibach), Erfolglose Behandlung skrofulöser Augenerkrankungen mit Antituberkuloseserum M a r morek. Wien. med. Wochenschr. 1907. Nr. 38 .

8. Cambias o, Annali dell' Ist. Maragliano. Bd. 3. 1909. S. 236.

9. Ferrer, Pi er a, Behandlung der Tuberkulose mit M a r a g li a n o s Serum. Gazetta degli osped. 1904. Nr. 124.

10. Figari, Immunisierung und Heilwert des Tuberkuloseserums Ma $\mathbf{r a g}$ lianos. Riform. med. 1905. Nr. 10.

11. Frey (Davos), Meine Erfahrungen mit dem Antituberkuloseserum Marmor e k. Münch. med. Wochenschr. 1904. Nr. 44.

- Meine Erfahrungen mit dem Antituberkuloseserum Marmorek.

II. Serie. Wien. klin. therap. Wochenschr. 1905. Nr. 42.

- - III. Serie. Deutsche med. Presse 1907. Nr. 21.

- Das Tuberkuloseserum M a r m o r e k. Zeitschr. f. Tub. Bd. XIII. H. 2. 1908.

12. Gang hofner (Prag), Frfahrungen mit dem Serum M a rmorek. Wien. klin. Wochenschr. 1909. Nr. 3. S. 92.

13. Glaessner, Die Anwendung und die Erfolge des Marmorekserum. Deutsche med. Wochenschr. 1909. Nr. 17.

- Das Marmorekserum bei der Behandlung der chirurgischen Tuberkulose. Zeitschr. f. Tub. Bd. 16. H. 5.

14. Grün er, Behandlung interner und chirurgischer Tuberkulose mit dem Antituberkuloseserum M a r m o r e k. Wien. klin. Wochenschr. 1908. Nr. 38.

15. Hoffa, Über das M a r morek serum in der Therapie der chirurgischen Tuberkulose. Berl. klin. Wochenschr. 1906. Nr. 44.

- Verhandlung der Berl. med. Gesellschaft vom 8. Mai 1905. Berl. klin. Wochenschr. 1907. Nr. 20. S. 646.

16. Hohmeyer, Die Behandlung chirurgischer Tuberkulose mit dem Antituberkuloseserum M a r mor e k. Münch. med. Wochenschr, 1908. Nr. 15.

17. Holmboe. (Norwegen), Über einige Fälle von Lungentuberkulose mit Dr. M a r m or ek s Antituberkuloseserum behandelt. Zeitschr. f. Tub. Bd. 12. Heft 2. 
18. van $\mathrm{Hu}$ ellen, Verhandlungen der Berl. med. Gesellschaft vom 8. V. 1907. Berl. klin. Wochenschr. 1907. Nr. 20. S. 645.

- Weitere Erfahrungen über die Wirksamkeit des Antituberkuloseserums Marmorek. Deutsche Zeitschr. f. Chir. Bd. 95. H. 15.

19. Karwacki, Der Einfluss des Serums Maragliano auf den Verlauf der Tuberkulose bei Tieren. Denkschrift d. Warsch. med. Ges. 1905.

20. Köhler (Holsterhausen), Das Tuberkuloseserum Marmorek. Zeitschr. f. Tub. Bd. 13. H. 2. 1908.

- Erfolgkontrollen bei Behandlung der Lungentuberkulose mit Serum M a r mor e k. Ibid. Bd. 16. H. 6. 1910.

21. Köhler-Lenzmann, Die therapeutische Beeinflussung der inneren und äusseren Tuberkulose durch Tuberkulin und verwandte Mittel. Beihefte z. med. Klinik. V. Jahrg. 1909. H. 2.

22. K ra.us, F. (Berlin), Immunität bei Tuberkulose. Zeitschr. f. Tub. Bd. 7. H. 3. 1905 .

23. Kroki ewiczu. Englünder (Krakau), Erfahrungen mit Marmoreks Serum bei der Lungenphthise. Wien. klin. Wochenschr. 1906. Nr. 11 vom 15. März.

24. Mann, G. (Triest), Das Serum Marmorek bei Lungentuberkulose. Wien. klin. Wochenschr. 1906. Nr. 42.

25. Maragliano, Passive Immunisierung. Gazz. degli Ospedali e delle clin. 1903. Nr. 53.

- La terapia specifica della tuberculosi et la sua vaccinazione. Ibid. 1904. Nr. 124.

- Die spezifische Therapie der Tuberkulose. Berl. klin. Wochenschr. 1904.

Nr. 24.

- Ann. dell' istit. M a r a g li a no Bd. 3. 1909. S. 195.

26. Marmorek, Sérum et vaccin antituberculeux. Arch. gén. d. Méd. 1903. Nr. 47.

- Antituberkuloseserum und Vakzin. Berl. klin. Wochenschr. 1903. Nr. 48.

- Weitere Untersuchungen über den Tuberkelbazillus und das Antituberkuloseserum. Berl. klin. Wochenschr. 1907. Nr. 20.

27. Mircoli, Veröffentlichung auf dem internat. Tuberkulose-Kongress, Neapel 1905.

28. Monod (Paris), Sur la sérothérapie dans la tuberculose. Bulletin de l'Academie de Médecine, Paris 1907, séance du 15 janvier.

29. Neporoschny, Antituberkuloseserum. Archiv f. biol. Wissenschaften. 1908. Bd. 13. H. 4 u. 5. Russ. med. Rundschau. 1908. Nr. 1. Zeitschr. f. Tub. Bd. 11. H. 1.

30. Niemann, Über Tuberkuloseserum. Münch. med. Wochenschr. 1897. Seite 59.

31. P a ters on, Zentralblatt für Bakteriol. 1897. Bd. 24. S. 115.

32. Pawlowsky, über die Immunisierung gegen die Tuberkulose und ihre Serumbehandlung. Zeitschr. f. Tub. Bd. XVII. H. 1. 1911.

33. P f e iffer und Trunk, Beobachtungen über die Behandlung ron Lungentuberkulose mit M a r m or e k serum. Zeitschr. f. Tub. 1907. Bd. 11. H. 4.

34. Richet und Héricourt, Compt. rend. de biol. 1890. S. 316 u. 630; 1891, S. 335 .

35. Sievers, Om behandling i Finland af tuberkulos med Marmoreks 
330 P Piel: Die bisherigen sero-therapentischen Bestrebungen bei Tuberkulose. [ 28 antituberkuloseserum. Finska Läkaresällskapets Handlingar 1906. S. 285 bis 295 .

36. Soriani, Behandlung der Tuberkulose mil Serum Maragliano. Gaz. d. ospedali. Nr. 124. Deutsche med. Wochenschr. 1904. S. 1660.

37. $\mathrm{Schwartz}$ (Gleiwitz), Heilung eines Falles von Augentuberkulose durch M a rm oreks Serum. Deutsche med. Wochenschr. 1905. Nr. 34.

38. Ullmann (Znaim), Über meine Erfolge mit Dr. Marmoreks Antituberkuloseserum. Zeitschr. f. Tub. 1906. Bd. 10. H. 2. - Ibid. 1908. Bd. 1.2. H. 1.

39. Vi c c o lin i, Über Serum M a r a g li a n o. Gaz. degli osped. 1904. Nr. 124.

40. Vos (Hellendoorn, Holland), Über die rektale Anwendung des M a r m o r e kserums in der Lungentuberkulose. Zeitschr. f. Tub. Bd. 14. H. 5. 1909.

41. Wein, Die spezifische Behandlung der Tuberkulose, insbesondere mit M a r mor eks Serum. Pester med. chir. Presse 1908. Nr. 18. S. 427.

- Ibid. 1909. Nr. 1, 2 u. 3.

- Meine Erfahrungen mit Dr. M a r m or eks Antituberkuloseserum. Wiener med. Wochenschr. 1909. Nr. 10. 